\title{
Effectiveness of Ipragliflozin for Reducing Hemoglobin A1c in Patients With a Shorter Type 2 Diabetes Duration: Interim Report of the ASSIGN-K Study
}

\author{
Kotaro Iemitsu ${ }^{\mathrm{a}}$, Takehiro Kawata ${ }^{\mathrm{a}}$, Takashi Iizuka ${ }^{\mathrm{a}}$, Masahiro Takihata ${ }^{\mathrm{a}}$, Masahiko Takai ${ }^{\mathrm{a}}$, \\ Shigeru Nakajima ${ }^{a}$, Nobuaki Minami ${ }^{\mathrm{a}}$, Shinichi Umezawa ${ }^{\mathrm{a}}$, Akira Kanamori ${ }^{\mathrm{a}}$, Hiroshi Takeda ${ }^{\mathrm{a}}$, \\ Shogo Ito ${ }^{a}$, Taisuke Kikuchia, Hikaru Amemiya ${ }^{a}$, Mizuki Kaneshiro ${ }^{a}$, Atsuko Mokubo ${ }^{\text {, }}$ \\ Tetsuo Takuma ${ }^{a}$, Hideo Machimura ${ }^{a}$, Keiji Tanaka ${ }^{a}$, Taro Asakura ${ }^{a}$, Akira Kubota ${ }^{a}$, Sachio Aoyanagia, \\ Kazuhiko Hoshino ${ }^{\text {a }}$, Masashi Ishikawa ${ }^{a}$, Yoko Matsuzawa ${ }^{\text {a }}$, Mitsuo Obana ${ }^{a}$, Nobuo Sasai ${ }^{a}$, \\ Hideaki Kaneshige ${ }^{a}$, Fuyuki Minagawa a , Tatsuya Saito ${ }^{a}$, Kazuaki Shinoda ${ }^{a}$, Masaaki Miyakawa ${ }^{a}$, \\ Yasushi Tanaka $^{\mathrm{b}}$, Yasuo Terauchic ${ }^{\mathrm{c}}$, Ikuro Matsuba ${ }^{\mathrm{a}, \mathrm{d}}$
}

\begin{abstract}
Background: Ipragliflozin is a selective sodium glucose co-transporter 2 inhibitor. The ASSIGN-K study is investigating the efficacy and safety of ipragliflozin for type 2 diabetes mellitus (T2DM) in the real-world clinical setting.
\end{abstract}

Methods: Japanese T2DM patients with inadequate glycemic control despite diet and exercise with/without pharmacotherapy were enrolled in an investigator-driven, multicenter, prospective, observational study examining the efficacy and safety of ipragliflozin treatment ( $50 \mathrm{mg} /$ day for 52 weeks). We performed interim analysis after 24 weeks.

Results: In 367 patients completing 24-week ipragliflozin therapy, hemoglobin A1c (HbA1c) decreased significantly from $8.07 \%$ at baseline to $7.26 \%$ in week $24(\mathrm{P}<0.001)$. The change in $\mathrm{HbA} 1 \mathrm{c}$ from treatment initiation to week 24 was $-0.88 \%$ in patients $<65$ years old versus $-0.55 \%$ in those $\geq 65$ years and $-0.92 \%$ in men versus $-0.70 \%$ in women (all $\mathrm{P}<0.001$ ). When baseline $\mathrm{HbA1}$ c was $<7 \%, 7 \%$ to $<$ $8 \%$, and $\geq 8 \%$, the change was $-0.18 \%,-0.45 \%$, and $-1.48 \%$, respectively ( $\mathrm{P}=0.5352, \mathrm{P}<0.001$, and $\mathrm{P}<0.001$, respectively). When baseline body mass index (BMI) was $<25,25$ to $<30$, and $\geq 30$, the

Manuscript submitted May 25, 2017, accepted June 13, 2017

aDiabetes Committee, Kanagawa Physicians Association, 3-1 Fujimi-cho, Naka-ku, Yokohama-shi, Kanagawa 231-0037, Japan

bDepartment of Internal Medicine, Division of Metabolism and Endocrinology, St. Marianna University School of Medicine, 2-16-1 Sugao, Miyamae-ku, Kawasaki-shi, Kanagawa 216-8511, Japan

'Department of Molecular Endocrinology and Diabetes Internal Medicine, Yokohama City University Graduate School of Medicine, 3-9 Fukuura, Kanazawa-ku, Yokohama-shi, Kanagawa 236-0004, Japan

${ }^{\mathrm{d} C o r r e s p o n d i n g ~ A u t h o r: ~ I k u r o ~ M a t s u b a, ~ M a t s u b a ~ M e d i c a l ~ C l i n i c, ~ 2-159 ~ T s u k-~}$ agoshi, Saiwai-ku, Kawasaki-shi, Kanagawa 212-0024, Japan.

Email: ikuro@matsuba-web.com

doi: https://doi.org/10.14740/jocmr3116w change was $-1.05 \%,-0.65 \%$, and $-0.87 \%$, respectively (all $\mathrm{P}<0.001$ ). Multiple regression analysis showed that $\mathrm{HbAlc}$ decreased more in patients with a higher baseline $\mathrm{HbAlc}$ or shorter duration of diabetes. An $\mathrm{HbA} 1 \mathrm{c}<7 \%$ was achieved in $33.3 \%$ of the patients, and their baseline $\mathrm{HbA} 1 \mathrm{c}$ was significantly lower than that of patients failing to achieve it $(\mathrm{P}<0.001)$. Adverse events (AEs) occurred in 106/451 patients $(23.5 \%)$, including $29.1 \%$ of patients aged 65 or older. Common AEs were vulvovaginal candidiasis (3.1\%) and genital pruritus $(1.8 \%)$. Serious AEs included urinary tract infection, unstable angina, and ketosis, which occurred in patients who did not suspend medication during acute illness.

Conclusions: Ipragliflozin significantly improved $\mathrm{HbA} 1 \mathrm{c}$ in T2DM patients with inadequate glycemic control. Improvement in $\mathrm{HbAlc}$ was significant irrespective of age, sex, baseline HbAlc, or BMI, but efficacy was greater with a higher baseline HbAlc and shorter duration of diabetes. For safe continuation of treatment, patients should be advised to suspend medication during acute illness.

Keywords: Body fat mass; Sodium glucose co-transporter 2 inhibitor; Ipragliflozin; Type 2 diabetes mellitus; Glycemic control

\section{Introduction}

After being absorbed and digested, glucose is filtered through the glomeruli of the kidneys and then reabsorbed in the proximal tubules, with sodium glucose co-transporter 2 (SGLT2) playing a major role in the reabsorption process $[1,2]$. SGLT2 inhibitors can be used to treat type 2 diabetes mellitus (T2DM) without targeting insulin secretion through reduction of blood glucose (BG) by inhibiting glucose reabsorption in the proximal renal tubules. Improvement in glycemic control by various SGLT2 inhibitors has been demonstrated in Japanese clinical studies [3-9], and these antidiabetic drugs have been approved in Japan since 2014. Both the body weight (BW) and blood pressure (BP) are decreased by SGLT2 in- 
hibitors, which can be used concomitantly with various other agents owing to their unique mechanism of action [10]. SGLT2 inhibitors were listed as an option for combination therapy in the 2015 treatment algorithms published in the EU and the USA [11]. In clinical trials, urinary tract and genital tract infections have been identified as characteristic adverse reactions to SGLT2 inhibitors. In addition, serious adverse reactions such as severe hypoglycemia, ketoacidosis, or generalized skin rashes have been reported in patients using SGLT2 inhibitors with insulin or sulfonylureas. Moreover, osmotic diuresis due to increased urinary excretion of glucose has been reported to cause dehydration, which has been suggested to be associated with cerebral infarction. Accordingly, the Committee on the Proper Use of SGLT2 Inhibitors of the Japan Diabetes Society has twice formulated recommendations for appropriate use of these drugs (in 2014 and 2016), listing precautions with regard to dehydration, urinary tract infection, and genital tract infection when SGLT2 inhibitors are administered to elderly patients concurrently with insulin or sulfonylureas and encouraging suspension or cessation of medication during acute illness. Because SGLT2 inhibitor therapy is associated with weight loss, these drugs are expected to be effective for obese T2DM patients with insulin resistance. In order to minimize adverse events (AEs), treatment should be tailored for each patient based on clinical characteristics. However, there have not been many reports about the relationship between the efficacy (reduction of hemoglobin A1c (HbA1c) and weight loss) or safety of SGLT2 inhibitors and patient characteristics.

Ipragliflozin is a selective SGLT2 inhibitor. A phase II dose-ranging study performed in Japanese patients with T2DM showed that administration of ipragliflozin at 100 $\mathrm{mg}$ daily reduced $\mathrm{HbA} 1 \mathrm{c}$ by $0.81 \%$ and $\mathrm{BW}$ by $2.10 \mathrm{~kg}$ in week 12 [3]. In this study, patients were stratified into groups with a lower baseline $\mathrm{HbAlc}(<8.4 \%)$ and a higher baseline HbA1c ( $\geq 8.4 \%)$, and the change in HbA1c during treatment was significantly larger in the latter group (P $<$ 0.001 ). In contrast, the change in HbAlc showed no significant difference between patients initiating treatment with ipragliflozin and those receiving add-on therapy $(\mathrm{P}=0.106)$ or between obese and non-obese patients $(P=0.228)$. In other previous studies of ipragliflozin, patients with higher baseline HbA1c levels showed a larger change in HbA1c $[4,12-14]$.

We have been conducting an investigator-initiated, multicenter, prospective clinical trial (the ASSIGN-K study) to examine the efficacy and safety of treatment with ipragliflozin for 52 weeks in the real-world setting, either as monotherapy after switching from other antidiabetic agents or in combination with prior therapy. We previously reported the results up to week 12 with respect to glycemic control, safety, and the influence of various patient characteristics $[15$, 16]. Detailed information has also been obtained about the changes in body composition up to 24 weeks of ipragliflozin therapy (submitted for publication). The present report is based on the results of interim analysis and describes the influence of various clinical characteristics (age, sex, duration of diabetes, body mass index (BMI), and baseline $\mathrm{HbAlc}$ ) on changes in $\mathrm{HbA} 1 \mathrm{c}$ and various other parameters up to 24 weeks.

\section{Patients and Methods}

\section{Study design}

ASSIGN-K is an investigator-driven, prospective, multicenter study evaluating the efficacy and safety of ipragliflozin as monotherapy or combination therapy in outpatients with T2DM [15]. The study was commenced at 33 centers in Kanagawa Prefecture, Japan in June 2014, with patient registration by electronic data capture being continued until January 31,2016 . All patients provided written informed consent to enrollment in this study.

\section{Patients}

The subjects were Japanese patients with T2DM who were at least 20 years old at the time of giving informed consent and had inadequate glycemic control with an $\mathrm{HbAlc} \geq 6.0$ (National Glycohemoglobin Standardization Program value) despite treatment for at least 12 weeks (diet alone, diet and exercise, or diet and exercise plus antidiabetic drug therapy).

Exclusion criteria were as follows: 1) a history of hypersensitivity to ipragliflozin, 2) a history of severe ketotic diabetic coma within the past 6 months, 3) severe infection, preoperative/postoperative state or severe trauma, and 4) severe renal impairment.

\section{Treatment}

Patients received oral ipragliflozin $(50 \mathrm{mg}$ once a day before or after breakfast) for 52 weeks. Concomitant use of other SGLT2 inhibitors was not permitted. In addition, treatment with diet, exercise, or specified health foods could not be started, discontinued, or modified during the study period. If possible, there were also no commencement, discontinuation, or dosage changes of medications for underlying diseases, such as antiplatelet agents, antihypertensive drugs, and lipid-lowering agents.

\section{Endpoints}

The primary efficacy endpoint of this study was the change in HbA1c after 52 weeks of ipragliflozin treatment, while the secondary efficacy endpoints were the changes in the fasting BG level, postprandial BG level, body composition, BW, waist circumference, serum lipids, free fatty acids, and BP, as well as improvement in $\mathrm{HbAlc}$ stratified by baseline patient characteristics. All efficacy endpoints were evaluated in weeks 4, 12, 24,36 , and 52 . Safety endpoints were the change in the blood level of ketone bodies after initiation of treatment, as well as AEs and adverse reactions.

The present interim analysis was performed in patients 


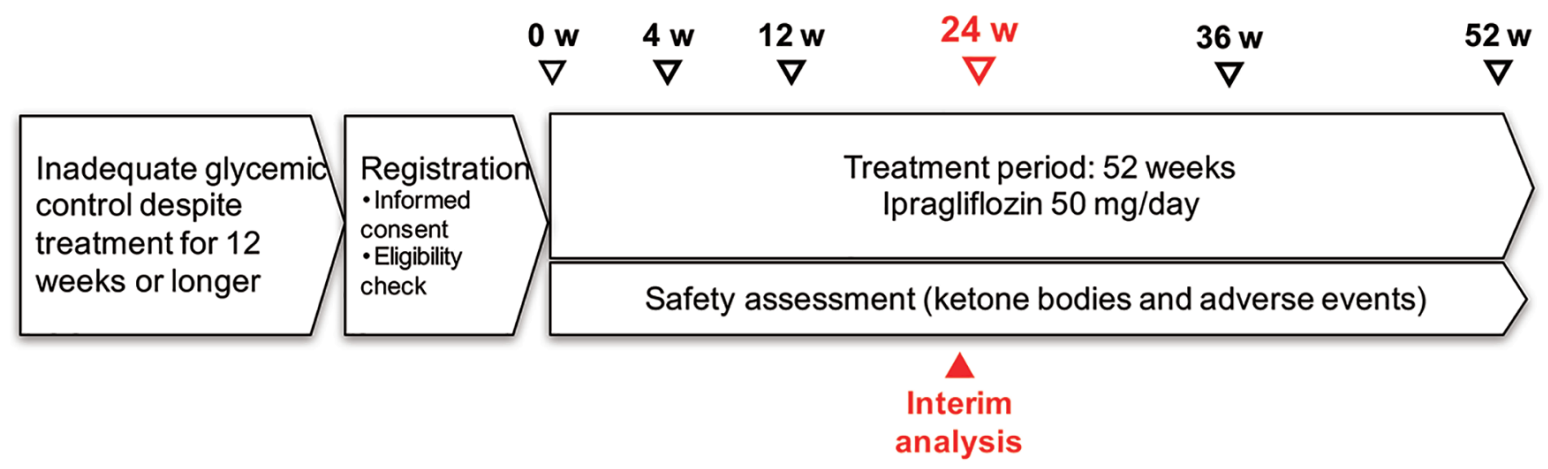

Figure 1. Study schedule.

who had been on treatment for more than 24 weeks as of March 2016 (Fig. 1). This report describes the relationship of various patient characteristics to changes in $\mathrm{HbAlc}$, lipids, hepatic function, and renal function up to week 24 .

\section{Statistical analysis}

Summary statistics were calculated or frequencies were determined for patient characteristics, efficacy endpoints, and changes from baseline. Analysis of variance was used to perform stratified analysis of the change in each endpoint from baseline to week 24 and the changes in HbAlc. Patient characteristics that influenced the changes in $\mathrm{HbAlc}$ were investigated by stepwise multiple regression analysis using a significance level of $\mathrm{P}<0.05$.

For safety assessment, the frequency of AEs and the percentage of patients with AEs were determined. Preferred Terms from the Medical Dictionary for Regulatory Activities, Japanese version 18.0 (Japanese Maintenance Organization, Tokyo, Japan) were employed for coding AEs, and System Organ Class terms were also used. Any AE for which a causal relationship with ipragliflozin could not be excluded was classified as an adverse reaction.

\section{Results}

\section{Patient characteristics}

A total of 367 patients were available for this interim analysis of efficacy and 451 patients were available for assessment of safety. Table 1 shows the characteristics of the patients included in the interim analysis of efficacy. Their mean age was 55.5 \pm 11.6 years and $77.2 \%$ were younger than 65 years. The male/ female ratio was nearly $1: 1$ and mean BMI was $29.4 \pm 5.3 \mathrm{~kg} /$ $\mathrm{m}^{2}$. The mean baseline $\mathrm{HbAl} \mathrm{c}$ was $8.01 \pm 1.43 \%$ and the duration of diabetes was $9.6 \pm 7.4$ years. Mean estimated glomerular filtration rate (eGFR) was $83.4 \pm 21.7 \mathrm{~mL} / \mathrm{min} / 1.73 \mathrm{~m}^{2}$, with 59 patients (13.1\%) having an eGFR $<60 \mathrm{~mL} / \mathrm{min} / 1.73$ $\mathrm{m}^{2}$.

Ipragliflozin was administered as initial antidiabetic thera- py in 79 patients $(17.5 \%)$, while it was added to current medication in 335 patients $(74.3 \%)$ and 37 patients $(8.2 \%)$ were switched from other antidiabetic agents.

\section{Changes in $\mathrm{HbA1c}, \mathrm{BG}$, and $\mathrm{BW}$}

Between baseline and week 24, HbA1c decreased significantly from $8.07 \%$ to $7.26 \%(-0.81 \%)(\mathrm{P}<0.001)$. In addition, fasting BG decreased significantly from 156.0 to $136.0 \mathrm{mg}$ / $\mathrm{dL}(-20.0 \mathrm{mg} / \mathrm{dL})$ and postprandial BG declined significantly from 184.7 to $147.3 \mathrm{mg} / \mathrm{dL}(-37.4 \mathrm{mg} / \mathrm{dL}$ ) (both $\mathrm{P}<0.001)$. BW showed a decrease from 79.6 to $77.0 \mathrm{~kg}(-2.6 \mathrm{~kg})$, BMI declined from 29.6 to $28.7 \mathrm{~kg} / \mathrm{m}^{2}$ or $\left(-0.9 \mathrm{~kg} / \mathrm{m}^{2}\right)$, and waist circumference showed a reduction from 99.9 to $97.0 \mathrm{~cm}(-2.6$ $\mathrm{cm})$. All of these changes were significant (all $\mathrm{P}<0.01$ ). In week 4, systolic BP showed a significant decrease from 133.1 to $127.9 \mathrm{~mm} \mathrm{Hg}(-5.2 \mathrm{~mm} \mathrm{Hg})$ and diastolic BP was significantly reduced from 79.1 to $76.5 \mathrm{~mm} \mathrm{Hg}(-2.6 \mathrm{~mm} \mathrm{Hg}$ ) (both $\mathrm{P}<0.0001$; Table 2). Similar reduction of BP was maintained up to week 24 .

\section{Influence of patient characteristics on the change in HbA1c}

Stratified analysis was carried out to determine the influence of age, sex, duration of diabetes, BMI, eGFR, and HbAlc at the start of treatment on the change in HbA1c in week 24. Age did not have a significant influence on the improvement in $\mathrm{HbAlc}$, with the mean change in $\mathrm{HbAl}$ c being $-0.88 \%$ in patients aged $<65$ years $(\mathrm{n}=294)$ and $-0.55 \%$ in those aged $\geq 65$ years $(\mathrm{n}=73)$ (both $\mathrm{P}<0.001)$. Gender also had no significant influence on the improvement in $\mathrm{HbA} 1 \mathrm{c}$, with the mean change being $-0.92 \%$ in men $(n=194)$ and $-0.70 \%$ in women $(\mathrm{n}=173)$ (both $\mathrm{P}<0.001)$. Baseline BMI was also not a significant factor. In patients with a baseline BMI of $<25$ (n $=72), 25-30(\mathrm{n}=153)$, and $\geq 30(\mathrm{n}=142)$, the mean change in $\mathrm{HbA} 1 \mathrm{c}$ was $-1.05 \%,-0.65 \%$, and $-0.87 \%$, respectively (all $\mathrm{P}<0.001$ ). However, baseline HbA1c had an influence on the change in HbA1c. In patients whose baseline HbA1c was < $7 \%(\mathrm{n}=80), 7-8 \%(\mathrm{n}=129)$, and $\geq 8 \%(\mathrm{n}=158)$, the mean change in $\mathrm{HbA} 1 \mathrm{c}$ was $-0.18 \%,-0.39 \%$, and $-1.48 \%$, respectively. Although significant improvement was not observed in 
Table 1. Clinical Characteristics of the Patients

\begin{tabular}{|c|c|}
\hline Number of patients & 451 \\
\hline Age, years, mean $\pm \mathrm{SD}$ & $55.5 \pm 11.6$ \\
\hline$<65$ years, $\mathrm{n}(\%)$ & $348(77.2)$ \\
\hline$\geq 65$ years, $n(\%)$ & $103(22.8)$ \\
\hline \multicolumn{2}{|l|}{ Sex } \\
\hline Male, n (\%) & $234(51.9)$ \\
\hline Female, $\mathrm{n}(\%)$ & $217(48.1)$ \\
\hline Body weight, $\mathrm{kg}$, mean $\pm \mathrm{SD}$ & $78.6 \pm 16.8$ \\
\hline Body mass index, $\mathrm{kg} / \mathrm{m}^{2}$, mean $\pm \mathrm{SD}$ & $29.4 \pm 5.3$ \\
\hline Waist circumference, $\mathrm{cm}$ & $99.8 \pm 12.0$ \\
\hline Hemoglobin A1c, $\%, *$ mean \pm SD $(n)$ & $8.01 \pm 1.43(451)$ \\
\hline Fasting blood glucose, $\mathrm{mg} / \mathrm{dL}$, mean $\pm \mathrm{SD}(\mathrm{n})$ & $156.4 \pm 48.0(197)$ \\
\hline Postprandial blood glucose, mg/dL, mean \pm SD (n) & $179.6 \pm 78.9(252)$ \\
\hline Duration of diabetes, years, mean \pm SD (n) & $9.6 \pm 7.4(451)$ \\
\hline Systolic blood pressure, $\mathrm{mm} \mathrm{Hg}$, mean \pm SD (n) & $133.1 \pm 17.2(448)$ \\
\hline Diastolic blood pressure, $\mathrm{mm} \mathrm{Hg}$, mean $\pm \mathrm{SD}(\mathrm{n})$ & $79.2 \pm 11.1(448)$ \\
\hline Estimated glomerular filtration rate, $\mathrm{mL} / \mathrm{min} / 1.73 \mathrm{~m}^{2}$, mean $\pm \mathrm{SD}(\mathrm{n})$ & $83.4 \pm 21.7(445)$ \\
\hline$<60 \mathrm{~mL} / \mathrm{min} / 1.73 \mathrm{~m}^{2}, \mathrm{n}(\%)$ & $59(13.1)$ \\
\hline$\geq 60 \mathrm{~mL} / \mathrm{min} / 1.73 \mathrm{~m}^{2}, \mathrm{n}(\%)$ & $386(85.6)$ \\
\hline \multicolumn{2}{|l|}{ Complications of diabetes } \\
\hline Diabetic nephropathy & $131(29.0)$ \\
\hline Diabetic retinopathy & $62(13.7)$ \\
\hline Diabetic neuropathy & $60(13.3)$ \\
\hline \multicolumn{2}{|l|}{ Prescribing pattern } \\
\hline Initial treatment & $79(17.5)$ \\
\hline Concomitant use & $335(74.3)$ \\
\hline Switching & $37(8.2)$ \\
\hline
\end{tabular}

*National Glycohemoglobin Standardization Program value. SD: standard deviation.

patients with a baseline $\mathrm{HbA} 1 \mathrm{c}<7 \%$, the reduction of $\mathrm{HbA} 1 \mathrm{c}$ was significant in the other subgroups with a baseline value of $7 \%$ or higher (both $\mathrm{P}<0.001$ ). With regard to the duration of diabetes, the change in $\mathrm{HbAlc}$ from baseline was $-1.02 \%$ in patients with a duration of $<5$ years $(n=100)$, while the change was $-0.89 \%$ at a duration of $5-10$ years $(n=90)$, $-0.77 \%$ at $10-15$ years $(n=76)$, and $-0.66 \%$ at $\geq 15$ years $(n$ =77). Significant reduction of HbA1c was observed irrespective of the duration of diabetes (all $\mathrm{P}<0.001$ ). With respect to renal function, the change in $\mathrm{HbA} 1 \mathrm{c}$ from baseline was $-0.86 \%$ in patients with an eGFR $\geq 60 \mathrm{~mL} / \mathrm{min} / 1.73 \mathrm{~m}^{2}(\mathrm{n}=$ 318 ) and $-0.46 \%$ in those with an eGFR $<60 \mathrm{~mL} / \mathrm{min} / 1.73$ $\mathrm{m}^{2}(\mathrm{n}=46)$, with significant improvements in HbA1c in both subgroups (both $\mathrm{P}<0.001$ ). With regard to the influence of the prescribing pattern, patients who were switched to ipragliflozin $(n=33)$ did not show significant improvement in HbAlc. However, both patients on concomitant therapy $(\mathrm{n}=$ $280)$ and those receiving initial treatment with ipragliflozin $(n=54)$ showed significant reduction of HbAlc $(-0.90 \%$ and
$-0.86 \%$, respectively, both $\mathrm{P}<0.001$ ) (Table 3 ).

\section{Changes in hepatic function, serum lipids, and renal function}

Investigation of the changes in hepatic function parameters from baseline to week 24 revealed that aspartate aminotransferase $(\mathrm{n}=354)$, alanine aminotransferase $(\mathrm{n}=357)$, and $\gamma$-glutamyltransferase $(n=358)$ were significantly reduced by 7.3, 10.2, and 15.7 IU/L, respectively (all $\mathrm{P}<0.001$ ). Regarding serum lipids, high-density lipoprotein cholesterol $(\mathrm{n}=112)$ was significantly elevated by $5.1 \mathrm{mg} / \mathrm{dL}$, while triglycerides $(\mathrm{n}=112)$ were significantly decreased by $27.3 \mathrm{mg} / \mathrm{dL}(\mathrm{P}<0.001$ and $\mathrm{P}$ $<0.01$, respectively). However, low-density lipoprotein cholesterol $(\mathrm{n}=110)$ did not show a significant change. Uric acid $(\mathrm{n}=$ 348 ) was significantly decreased by $0.45 \mathrm{mg} / \mathrm{dL}(\mathrm{P}<0.001)$. Although eGFR $(n=360)$ showed a significant decrease from 84.0 $\mathrm{mL} / \mathrm{min} / 1.73 \mathrm{~m}^{2}$ at baseline to $82.3 \mathrm{~mL} / \mathrm{min} / 1.73 \mathrm{~m}^{2}$ in week 24 $\left(-1.7 \mathrm{~mL} / \mathrm{min} / 1.73 \mathrm{~m}^{2}\right)(\mathrm{P}=0.05)$, the changes were not consist- 
Table 2. Changes in Various Parameters up to Week 24

\begin{tabular}{|c|c|c|c|c|c|}
\hline & $\mathbf{n}$ & Baseline & Week 4 & Week 12 & Week 24 \\
\hline Hemoglobin A1c, \% & 374 & $8.07 \pm 1.46$ & $7.66 \pm 1.22 * * *$ & $7.31 \pm 1.11^{* * *}$ & $7.26 \pm 1.05 * * *$ \\
\hline Fasting blood glucose, $\mathrm{mg} / \mathrm{dL}$ & 114 & $156.0 \pm 44.6$ & $136.7 \pm 36.8 * * *$ & $132.2 \pm 33.4 * * *$ & $136.0 \pm 33.2 * * *$ \\
\hline Homeostasis model assessment of insulin resistance & 51 & $4.46 \pm 3.96$ & $3.14 \pm 2.27 * * *$ & $3.16 \pm 2.36^{* * *}$ & $3.28 \pm 2.70 * * *$ \\
\hline Body weight, $\mathrm{kg}$ & 373 & $79.6 \pm 16.6$ & $78.4 \pm 16.4^{* * *}$ & $77.5 \pm 16.2 * * *$ & $77.0 \pm 16.2 * * *$ \\
\hline Waist circumference, $\mathrm{cm}$ & 342 & $99.9 \pm 12.1$ & $98.9 \pm 12.9^{* *}$ & $98.0 \pm 11.8^{* * *}$ & $97.0 \pm 11.7^{* * *}$ \\
\hline Systolic blood pressure, $\mathrm{mm} \mathrm{Hg}$ & 369 & $133.1 \pm 17.1$ & $127.9 \pm 16.4 * * *$ & $128.5 \pm 16.5^{* * *}$ & $128.2 \pm 16.8^{* * *}$ \\
\hline Diastolic blood pressure, $\mathrm{mm} \mathrm{Hg}$ & 369 & $79.1 \pm 10.9$ & $76.5 \pm 10.8^{* * *}$ & $76.6 \pm 11.1^{* * *}$ & $76.8 \pm 11.7 * * *$ \\
\hline Pulse rate, beats/min & 295 & $78.6 \pm 12.7$ & $79.6 \pm 12.2$ & $79.3 \pm 12.0$ & $78.6 \pm 12.2$ \\
\hline
\end{tabular}

Analysis of variance vs. baseline ${ }^{* *} \mathrm{P}<0.001,{ }^{* *} \mathrm{P}<0.01$.

Table 3. Influence of Patient Characteristics on Hemoglobin A1C

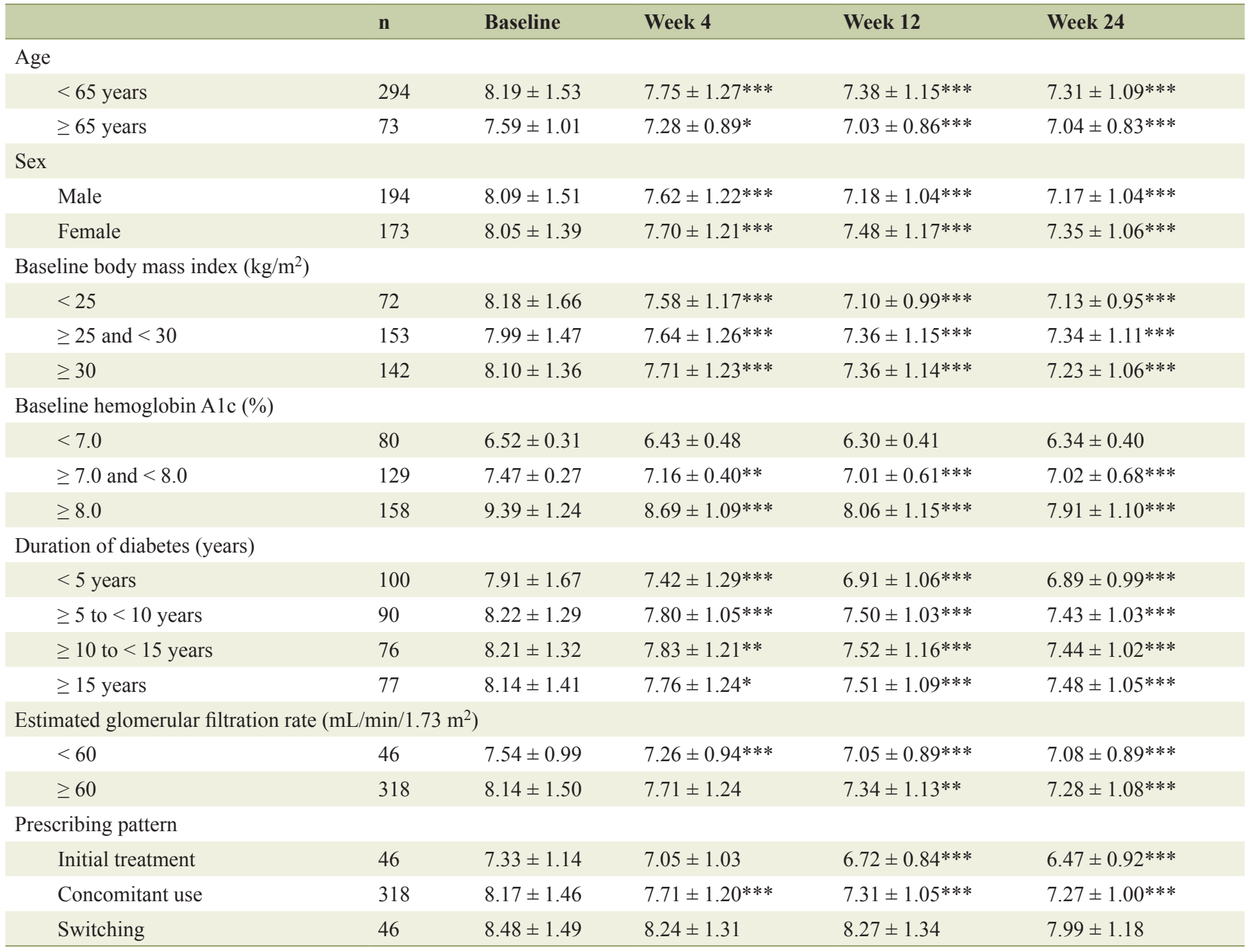

Analysis of variance vs. baseline ${ }^{* * *} \mathrm{P}<0.001,{ }^{* *} \mathrm{P}<0.01,{ }^{*} \mathrm{P}<0.05$. 
Table 4. Changes in Hepatic Function, Serum Lipids, and Renal Function

\begin{tabular}{|c|c|c|c|c|c|}
\hline & $\mathbf{n}$ & Baseline & Week 4 & Week 12 & Week 24 \\
\hline Aspartate aminotransferase, IU/L & 354 & $32.4 \pm 24.7$ & $30.5 \pm 23.1 * *$ & $27.7 \pm 21.4 * * *$ & $25.1 \pm 11.8^{* * *}$ \\
\hline Alanine aminotransferase, IU/L & 357 & $39.8 \pm 30.3$ & $36.6 \pm 28.4^{* *}$ & $32.8 \pm 22.3 * * *$ & $29.6 \pm 18.7^{* * *}$ \\
\hline Total cholesterol, mg/dL & 111 & $201.4 \pm 36.7$ & $197.9 \pm 37.7$ & $201.6 \pm 35.8$ & $203.3 \pm 38.9$ \\
\hline High-density lipoprotein cholesterol, mg/dL & 112 & $52.6 \pm 11.8$ & $52.5 \pm 11.5$ & $56.5 \pm 18.8$ & $57.7 \pm 16.5^{* * *}$ \\
\hline Uric acid, mg/dL & 348 & $5.4 \pm 1.2$ & $4.9 \pm 1.3 * * *$ & $5.0 \pm 1.2 * * *$ & $4.9 \pm 1.2 * * *$ \\
\hline Estimated glomerular filtration rate, $\mathrm{mL} / \mathrm{min} / 1.73 \mathrm{~m}^{2}$ & 360 & $84.0 \pm 21.5$ & $80.8 \pm 21.9^{* *}$ & $82.4 \pm 21.4^{*}$ & $82.3 \pm 21.3^{*}$ \\
\hline
\end{tabular}

Analysis of variance vs. baseline ${ }^{* *} \mathrm{P}<0.001,{ }^{* *} \mathrm{P}<0.01,{ }^{*} \mathrm{P}<0.05$.

Table 5. Multiple Regression Analysis of Factors Influencing the Change in Hemoglobin A1c in Week 24

\begin{tabular}{lllll}
\hline Influence rank & Independent variable & Standardized coefficient beta & Partial regression coefficient & P value \\
\hline & Constant & 0 & 2.295 & $<0.0001$ \\
1 & Hemoglobin A1c (baseline) & -0.691 & -0.519 & $<0.0001$ \\
2 & Switching to ipragliflozin & 0.166 & 0.615 & 0.0002 \\
3 & Duration of diabetes & 0.151 & 0.022 & 0.0096 \\
4 & Sex & 0.100 & 0.007 & 0.0842 \\
5 & Age & 0.076 & 0.011 & 0.1982 \\
\hline
\end{tabular}

$\mathrm{n}=328$, Stepwise analysis using the following independent variables: age, sex, duration of diabetes, baseline hemoglobin A1c, baseline body mass index, and prescribing pattern (initial monotherapy, concomitant use, or switching). Dependent variable: change in $\mathrm{HbA} 1 \mathrm{c}$.

ent. In fact, eGFR was decreased by $3.2 \mathrm{~mL} / \mathrm{min} / 1.73 \mathrm{~m}^{2}$ in week $4(\mathrm{P}<0.001)$, followed by a subsequent increase, and there was no significant change from week 12 in week 24 (Table 4).

\section{Multiple regression analysis of factors influencing the change in HbA1c}

Stepwise multiple regression analysis was carried out using the change in HbA1c from baseline in week 24 as the dependent variable and the age, sex, duration of diabetes, HbA1c, BMI, and medications at initiation of treatment as independent vari-

Table 6. Percentage of Patients Achieving Hemoglobin A1c < $7 \%$ and Their Characteristics at 24 Weeks

\begin{tabular}{llll}
\hline & $<\mathbf{7 \%}$ & $\mathbf{2 7 \%}$ & P value \\
\hline Number of patients (\%) & $97(33.8)$ & $190(66.2)$ & - \\
Female patients & $40.2 \%$ & $51.1 \%$ & 0.0817 \\
Age, years & 54.9 & 54.8 & 0.9477 \\
Duration of diabetes, years & 9.0 & 10.5 & 0.1092 \\
Baseline hemoglobin A1c, \% & 7.86 & 8.83 & $<0.001$ \\
Baseline body mass index, $\mathrm{kg} / \mathrm{m}^{2}$ & 29.14 & 29.39 & 0.7026 \\
\hline
\end{tabular}

${ }^{*}$ Not including patients achieving hemoglobin $\mathrm{A} 1 \mathrm{c}<7 \%$ at baseline. ables (Table 5). In relation to the change in HbAlc, the standardized coefficient beta for baseline $\mathrm{HbAlc}$ and the duration of diabetes was -0.691 and 0.151 , respectively, demonstrating that a higher baseline $\mathrm{HbA} 1 \mathrm{c}$ and shorter disease duration were associated with greater reduction of $\mathrm{HbA1c}(\mathrm{P}<0.0001$ and $\mathrm{P}$ $=0.0002$, respectively). Moreover, the standardized coefficient beta was 0.166 for the switching group, indicating that switching to ipragliflozin was associated with a smaller reduction of HbA1c $(\mathrm{P}<0.0001)$. However, baseline BMI did not influence the change in $\operatorname{HbAlc}(\mathrm{P}=0.1982)$.

\section{Percentage of patients achieving an $\mathrm{HbA1c}<7 \%$ and their characteristics}

An $\mathrm{HbA} 1 \mathrm{c}<7 \%$ was achieved in $33.8 \%$ of the patients. A lower baseline HbA1c was associated with a higher achievement rate $(\mathrm{P}<0.001)$, but the sex, age, duration of diabetes, and baseline BMI did not significantly influence the decrease in $\mathrm{HbA1c}(\mathrm{P}=0.0817, \mathrm{P}=0.9477, \mathrm{P}=0.1092$, and $\mathrm{P}=0.7026$, respectively) (Table 6).

\section{Safety}

AEs occurred in $106(23.5 \%)$ of the 451 patients in the safety 
analysis set, and were detected in $29.1 \%$ of patients aged 65 years or older $(n=103)$. The most common AE was vulvovaginal candidiasis (14 patients, 3.1\%), followed by cystitis (eight patients, 1.8\%), genital pruritus (eight patients, 1.8\%) and upper respiratory tract infection (eight patients, $1.8 \%$ ). Serious AEs occurred in eight patients, and a causal relationship was not ruled out for four of them, including three patients who developed ketosis, unstable angina, and urinary tract infection when they did not suspend medication during acute illness.

\section{Discussion}

The ASSIGN-K study is performing evaluation of ipragliflozin in the real-world clinical setting, allowing us to verify whether the results obtained in routine clinical practice are consistent with those of previous Japanese clinical studies.

\section{Changes in HbA1c}

Similar to findings reported previously [14], the change in $\mathrm{HbA} 1 \mathrm{c}$ from baseline through week 24 was $-0.81 \%(\mathrm{P}<$ 0.001). This result is consistent with data obtained in other Japanese clinical studies of ipragliflozin. When the changes in HbA1c were assessed over the treatment period, a significant decrease of $0.41 \%$ was observed from week 4 . The decrease was $0.76 \%$ in week 12 , showing an additional significant reduction of BG compared with week 4. A further decrease, $-0.81 \%$ versus baseline, was seen in week 24 , although there was no significant difference from week 12. Similar improvement in HbA1c over time was also noted up to week 12 in the phase II dose-finding study [3]. The improvement in HbA1c by week 4 in the present study may have been related to increased urinary glucose excretion, although urinary glucose excretion would subsequently be limited by increased SGLT1 activity and increased SGLT2 expression. It is possible that the subsequent ongoing decline of HbAlc during the study was due to improvement in insulin resistance as a result of the suppression of glucose toxicity and reduction of BW. A phase II study conducted outside Japan identified a correlation between weight loss and improvement in insulin sensitivity [17].

\section{Changes in BW}

The change in BW from baseline through week 24 was $-2.6 \mathrm{~kg}$ $(\mathrm{P}<0.001)$. Thus, reduction of $\mathrm{BW}$ was maintained throughout 24 weeks, suggesting that it was related to changes in both body water and body fat. In this study, both body water and body fat showed a significant decrease by week 4 . However, body fat continued to decrease from week 4 through week 24 , while there was no significant change in body water. This suggests that weight loss from the initiation of ipragliflozin treatment up to week 4 was directly related to loss of water due to osmotic diuresis associated with increased urinary glucose excretion, while weight loss from week 4 through week 24 occurred due to reduction of body fat. A Japanese study showed that about $50 \%$ of BW loss was due to reduced body fat and about $20 \%$ was attributable to loss of extracellular fluid [18]. In the present study, there was no significant change in muscle mass by week 24 , suggesting that weight loss was mainly due to a decrease in both body fluid and body fat up to week 4 , while reduction of body fat subsequently played the major role.

\section{Changes in hepatic function, serum lipids, and renal func- tion}

Previous clinical studies of SGLT2 inhibitors have revealed significant improvement in hepatic function markers or a similar trend $[19,20]$. In the present study, hepatic function markers (aspartate aminotransferase, alanine aminotransferase, and $\gamma$-glutamyltransferase) were significantly decreased in week 4 (all $\mathrm{P}<0.01)$ and also in week $24(-7.3,-10.2$, and $-15.7 \mathrm{IU} / \mathrm{L}$, respectively; all $\mathrm{P}<0.001)$. Improvement in these markers suggests an improvement in hepatic insulin sensitivity. T2DM is associated with an increased frequency of non-alcoholic fatty liver disease and/or non-alcoholic steatohepatitis [21], and approximately half of the patients in our study had fatty liver. Thus, ipragliflozin may improve fatty liver, but clinical studies with hepatic imaging would be needed for confirmation. With respect to lipid parameters, low-density lipoprotein cholesterol showed no significant change in week 24 , whereas highdensity lipoprotein cholesterol was significantly increased by $5.1 \mathrm{mg} / \mathrm{dL}(\mathrm{P}<0.001)$ and triglycerides were significantly decreased by $-27.3 \mathrm{mg} / \mathrm{dL}(\mathrm{P}<0.01)$. Improvement in the serum lipid profile is beneficial for prevention of cardiovascular disease, as is weight loss and the reduction of BP $(-4.9 \mathrm{~mm}$ $\mathrm{Hg}$ for systolic $\mathrm{BP}$ and $-2.3 \mathrm{~mm} \mathrm{Hg}$ for diastolic BP, both $\mathrm{P}$ $<0.001)$. In 2016, the EMPA-REG RENAL trial showed that empagliflozin significantly reduced the composite renal endpoint by $39 \%$ compared with the placebo group $(\mathrm{P}<0.001)$, but eGFR did not decrease significantly [22]. In the present study, eGFR was significantly decreased by $3.2 \mathrm{~mL} / \mathrm{min} / 1.73$ $\mathrm{m}^{2}$ in week 4 , but increased again after that. No significant change in eGFR was observed after week 12 and it was only decreased by $1.7 \mathrm{~mL} / \mathrm{min} / 1.73 \mathrm{~m}^{2}$ compared with baseline in week 24 ( $\mathrm{P}<0.05)$. These findings may indicate that regulation of excessive glomerular filtration resulted in an apparent decline of eGFR and that ipragliflozin may also have a longterm renoprotective effect.

\section{Clinical factors influencing HbA1c}

Stratified analysis confirmed that significant improvement in $\mathrm{HbA} 1 \mathrm{c}$ in week 24 was consistently observed irrespective of the age, sex, duration of diabetes, BMI, eGFR, and HbA1c at initiation of treatment. Analysis of clinical characteristics influencing $\mathrm{HbAlc}$ showed that baseline $\mathrm{HbAlc}$ and the duration of diabetes were correlated with the change in HbA1c, as was demonstrated by our previous analysis up to week 12 [16]. That is, the reduction of $\mathrm{HbA} 1 \mathrm{c}$ with ipragliflozin treatment was greater with a higher baseline $\mathrm{HbAlc}$ or shorter duration 
of diabetes. Similar to our findings in week 12, patients with a higher baseline HbA1c have greater urinary excretion of glucose, and the effect of ipragliflozin might have been more pronounced. In a phase II clinical study of ipragliflozin performed in Japanese patients with T2DM [2], a higher baseline HbA1c was also associated with larger changes in HbAlc. With regard to the influence of the duration of diabetes, expression of SGLT2 is enhanced and the threshold for urinary excretion of glucose is increased as the duration of disease becomes longer, resulting in decreased urinary excretion of glucose. In addition, secretion of insulin is reduced. These changes might have reduced the response to ipragliflozin in patients with a long disease duration. Baseline BMI did not influence the change in HbA1c. Regarding the influence of the prescribing pattern, patients who were switched to ipragliflozin did not show improvement in $\mathrm{HbA} 1 \mathrm{c}$, but detailed analysis of the long-term effect is needed to understand this result. In $33 \%$ of the patients, an $\mathrm{HbA} 1 \mathrm{c}<7 \%$ was achieved in week 24 . While changes in $\mathrm{HbA} 1 \mathrm{c}$ were larger in patients with a higher baseline $\mathrm{HbA} 1 \mathrm{c}$ level, patients who achieved $<7 \%$ had a significantly lower baseline HbAlc than those who could not achieve it $(\mathrm{P}<$ 0.001). Taken together with the results of multiple regression analysis, it can be suggested that earlier initiation of ipragliflozin therapy may achieve greater improvement in glycemic control.

\section{Safety}

Common AEs included urinary tract and genital tract infections, respiratory tract infections, gastrointestinal disturbances, and skin rashes. These AEs were comparable to those reported in Japanese clinical studies of ipragliflozin and other SGLT2 inhibitors [3-9]. Serious AEs included ketosis, unstable angina, and urinary tract infection in three patients who did not suspend medication when they developed acute illness with vomiting and diarrhea. This result emphasizes the importance of patient education about suspending medication during illness. Patients with a higher baseline HbA1c showed increased urinary glucose excretion and osmotic diuresis may be greater for 4 weeks after initiation of ipragliflozin treatment. Therefore, patients with a high $\mathrm{HbAlc}$ should be encouraged to maintain sufficient water intake.

\section{Conclusion}

This interim analysis of the ASSIGN-K study investigated the clinical characteristics influencing changes in HbAlc in 367 patients who completed 24 weeks of treatment with ipragliflozin. Both $\mathrm{HbA} 1 \mathrm{c}$ and BW showed a significant decrease in week 4 of treatment and further significant reduction of these parameters occurred from week 4 through week 24. A higher baseline $\mathrm{HbAlc}$ and shorter duration of diabetes were associated with greater improvement in $\mathrm{HbA1c}$, while baseline BMI did not have any influence. The reduction of BW was related to a decrease in both body water and body fat up to week 4, followed by loss of body fat thereafter. Muscle mass was not significantly reduced. Improvement in BP and serum lipids was noted along with weight loss, and these changes may be beneficial for preventing cardiovascular disease. An important objective of this study is to validate the efficacy of ipragliflozin in the real-world clinical setting, and the results obtained so far have been consistent with data from previous clinical studies in Japan. In summary, our findings indicate that SGLT2 inhibitors may achieve greater efficacy in patients with a higher baseline HbA1c and shorter disease duration, suggesting that re-examination of the current treatment policies for diabetes may be warranted.

\section{Disclaimer}

This research was planned and designed by the investigators. The company was not involved in the study design, patient enrollment, data aggregation and analysis, data interpretation, or preparation of this report.

\section{Grant Support}

This research was financially supported by Astellas Pharma, Inc. (Tokyo, Japan).

\section{References}

1. Kanai Y, Lee WS, You G, Brown D, Hediger MA. The human kidney low affinity $\mathrm{Na}+$ /glucose cotransporter SGLT2. Delineation of the major renal reabsorptive mechanism for D-glucose. J Clin Invest. 1994;93(1):397404.

2. Wright EM, Hirayama BA, Loo DF. Active sugar transport in health and disease. J Intern Med. 2007;261(1):3243.

3. Kashiwagi A, Kazuta K, Yoshida S, Nagase I. Randomized, placebo-controlled, double-blind glycemic control trial of novel sodium-dependent glucose cotransporter 2 inhibitor ipragliflozin in Japanese patients with type 2 diabetes mellitus. J Diabetes Investig. 2014;5(4):382391.

4. Kashiwagi A, Kawano H, Kazuta K. Long-term safety, tolerability and efficacy of ipragliflozin in Japanese patients with type 2 diabetes mellitus - IGNITE Study. Jpn Pharmacol Ther. 2015;43(1):85-100.

5. Seino Y, Sasaki T, Fukatsu A, Ubukata M, Sakai S, Samukawa Y. Efficacy and safety of luseogliflozin as monotherapy in Japanese patients with type 2 diabetes mellitus: a randomized, double-blind, placebo-controlled, phase 3 study. Curr Med Res Opin. 2014;30(7):1245-1255.

6. Kaku K, Watada H, Iwamoto Y, Utsunomiya K, Terauchi Y, Tobe K, Tanizawa Y, et al. Efficacy and safety of monotherapy with the novel sodium/glucose cotransporter-2 inhibitor tofogliflozin in Japanese patients with type 2 diabetes mellitus: a combined Phase 2 and 3 randomized, placebo-controlled, double-blind, parallel-group compar- 
ative study. Cardiovasc Diabetol. 2014;13:65.

7. Inagaki N, Kondo K, Yoshinari T, Kuki H. Efficacy and safety of canagliflozin alone or as add-on to other oral antihyperglycemic drugs in Japanese patients with type 2 diabetes: A 52-week open-label study. J Diabetes Investig. 2015;6(2):210-218.

8. Kaku K, Maegawa H, Tanizawa Y, Kiyosue A, Ide Y, Tokudome T, Hoshino Y, et al. Dapagliflozin as monotherapy or combination therapy in Japanese patients with type 2 diabetes: an open-label study. Diabetes Ther. 2014;5(2):415-433.

9. Kadowaki T, Haneda M, Inagaki N, Terauchi Y, Taniguchi A, Koiwai K, Rattunde H, et al. Efficacy and safety of empagliflozin monotherapy for 52 weeks in Japanese patients with type 2 diabetes: a randomized, double-blind, parallel-group study. Adv Ther. 2015;32(4):306-318.

10. Kurosaki E, Ogasawara H. Ipragliflozin and other sodium-glucose cotransporter-2 (SGLT2) inhibitors in the treatment of type 2 diabetes: preclinical and clinical data. Pharmacol Ther. 2013;139(1):51-59.

11. Inzucchi SE, Bergenstal RM, Buse JB, Diamant M, Ferrannini E, Nauck M, Peters AL, et al. Management of hyperglycemia in type 2 diabetes, 2015: a patient-centered approach: update to a position statement of the American Diabetes Association and the European Association for the Study of Diabetes. Diabetes Care. 2015;38(1):140149.

12. Kashiwagi A, Isaka H, Takinami Y, Kazuta K, Utsuno A, Yoshida S. Long-term safety, tolerability and efficacy of ipragliflozin in combination with an $\alpha$-glucosidase inhibitor in Japanese patients with type 2 diabetes mellitus inadequately controlled with an $\alpha$-glucosidase inhibitor alone - AGLOW Study. Jpn Pharmacol Ther. 2014;42(12): 923939. (Japanese article with English abstract).

13. Kashiwagi A, Isaka H, Kawano H, Kazuta K, Utsuno A, Yoshida S. Long-term safety, tolerability and efficacy of ipragliflozin in combination with a dipeptidyl peptidase-4 inhibitor in Japanese patients with type 2 diabetes mellitus inadequately controlled with a dipeptidyl peptidase-4 inhibitor alone - DAYLIGHT Study. Jpn Pharmacol Ther. 2014;42(12):941-957. (Japanese article with English abstract).

14. Kashiwagi A, Isaka H, Nakahama H, Kazuta K, Utsuno A, Yoshida S. Long-term safety, tolerability and efficacy of ipragliflozin in combination with a nateglinide in Japanese patients with type 2 diabetes mellitus inadequately controlled with nateglinide alone - CANDLE Study. Jpn Pharmacol Ther. 2014;42(12):959-975. (Japanese article with English abstract).

15. Iizuka $T$, Iemitsu $K$, Takihata $M$, Takai $M$, Nakajima $S$, Minami N, Umezawa S, et al. Efficacy and safety of ipragliflozin in Japanese patients with type 2 diabetes: interim outcome of the ASSIGN-K study. J Clin Med Res. 2016;8(2):116-125.

16. Iemitsu K, Iizuka T, Takihata M, Takai M, Nakajima S, Minami N, Umezawa S, et al. Factors influencing changes in hemoglobin A1c and body weight during treatment of type 2 diabetes with ipragliflozin: interim analysis of the ASSIGN-K study. J Clin Med Res. 2016;8(5):373378.

17. Schwartz SL, Akinlade B, Klasen S, Kowalski D, Zhang W, Wilpshaar W. Safety, pharmacokinetic, and pharmacodynamic profiles of ipragliflozin (ASP1941), a novel and selective inhibitor of sodium-dependent glucose cotransporter 2 , in patients with type 2 diabetes mellitus. Diabetes Technol Ther. 2011;13(12):1219-1227.

18. Martinelli M, Cordioli E, Rosato F. [Electrocardiographic changes during administration of mannitol in subjects with ischemic cardiopathy (preliminary observations)]. Boll Soc Ital Cardiol. 1977;22(10):1867-1874.

19. Kashiwagi A, Yoshida S, Nakamura I, Kazuta K, Ueyama E, Takahashi H, Satomi H, et al. Efficacy and safety of ipragliflozin in Japanese patients with type 2 diabetes stratified by body mass index: A subgroup analysis of five randomized clinical trials. J Diabetes Investig. 2016;7(4):544-554.

20. Leiter LA, Forst T, Polidori D, Balis DA, Xie J, Sha S. Effect of canagliflozin on liver function tests in patients with type 2 diabetes. Diabetes Metab. 2016;42(1):25-32.

21. Jimba S, Nakagami T, Takahashi M, Wakamatsu T, Hirota $\mathrm{Y}$, Iwamoto $\mathrm{Y}$, Wasada T. Prevalence of non-alcoholic fatty liver disease and its association with impaired glucose metabolism in Japanese adults. Diabet Med. 2005;22(9):1141-1145.

22. Wanner C, Inzucchi SE, Lachin JM, Fitchett D, von Eynatten M, Mattheus M, Johansen OE, et al. Empagliflozin and progression of kidney disease in type 2 diabetes. $\mathrm{N}$ Engl J Med. 2016;375(4):323-334. 